\title{
Physicians' knowledge and practice on death certification in the North West Bank, Palestine: across sectional study
}

\author{
Jamal A. S. Qaddumi ${ }^{1 *}$, Zaher Nazzal ${ }^{1}$, Allam Yacoub $^{2}$ and Mahmoud Mansour ${ }^{3}$
}

\begin{abstract}
Background: Mortality data are essential for many aspects of everyday public health practices at both national and international levels. Despite the current developments in various aspects of the medical field, the apparent inability of physicians to complete death notification forms (DNF) accurately is still worldwide concern. The aim of this study is to assess the physicians' knowledge and practice on completing the DNF.

Methods: A self-administered questionnaire was distributed to 200 physicians in governmental and non-governmental hospitals in the North West-Bank in Palestine. Furthermore, a case scenario was included in the questionnaire and physicians were asked to fill the cause of death section. The percentage of errors committed while completing the cause of death section were computed. A Chi square test was used to assess the association between physicians' characteristics and their responses.

Results: Only $40.6 \%$ of the participants completed the cause of death section correctly. The immediate and underlying causes of death were correctly identified by $48.7 \%$ and $71.3 \%$ of physicians, respectively. Almost one-fifth (17.3\%) of physicians wrote the mechanism of death without reporting the underlying cause of death and $14.7 \%$ of them reported the sequence of events leading to death incorrectly.

Conclusions: Physicians' knowledge and practice on completing the DNF is poor and insufficient, which may seriously affect the accuracy of mortality data. Complicated cases, problems in the current design of the DNFs and lack of training were the most common factors contributing to inaccuracy in death certification. We recommend offering periodical training workshops on completing the DNF to all physicians, and developing a manual on completing the DNFs with clear instructions and guidelines.
\end{abstract}

Keywords: Physicians' knowledge, Practice, Death certification

\section{Background}

Physicians are usually required to report the cause-of-death (COD) sequence on a death notification form [1-3]. Accurate COD reporting is a prerequisite for good quality mortality statistics required for health policy decisions [2]. Physicians have to be familiar with international recommendations for completing the DNF. It is important that the DNF should be completed by the physician who is most fully informed about the last illness of the deceased [3].

\footnotetext{
* Correspondence: jamal9877@najah.edu

${ }^{1}$ Faculty of Medicine and Health Sciences, An-Najah National University, PO box 7, Nablus, Palestine

Full list of author information is available at the end of the article
}

Briefly, the national DNF which was structured based on international guidelines [4] is composed of two sections: The demographic characteristics and the COD sections. The COD section consists of two parts: Part I for reporting the chain of events leading directly to death, with the immediate COD on the first line and the underlying COD on the lowest used line, and Part II for reporting all other significant diseases, conditions, or injuries that contributed to death.

Despite of the World Health Organization's (WHO) efforts on adopting guidelines and updating the format, unfortunately, errors in death notification are common [5], and have been noted worldwide [6]. Many studies assessed the physicians' knowledge and practice on 
completing the DNF and showed different types of errors and concluded that the physicians lack adequate knowledge, training and experience for completing death certificates [7]. A study conducted in the USA aimed to examine the experiences and opinions of physician residents in New York City on the accuracy of the COD reporting system; it concluded that most resident physicians believed that the current COD reporting system is inaccurate [8].

Different types of errors could occur at various stages of the COD reporting process, ranging from incomplete notification and using abbreviations, to inaccurate cause and manner of death [9]. One classification method divides the errors into major and minor [10]. Major errors include: (I) Incorrect sequencing where the chain of events leading directly to death are written in an order that is not scientifically appropriate; (II) competing causes of death occur when two or more causally unrelated, etiologically specific diseases are listed in part I of the DNF; (III) no acceptable cause of death is documented when signs, symptoms or ill-defined terms such as old age or severe headache are listed in part I of the DNF; (IV) no underlying cause of death after mechanism; this occurs if no underlying cause of death is reported and the notifying physician only uses mechanism of death or reported mechanism of death with incorrect underlying cause of death or there is no link between them. Minor errors include absence of time intervals for each diagnosis, using abbreviations, writing irrelevant information and illegible handwriting.

The aim of this study is to assess physicians' knowledge and practice on completing the DNF in order to improve the quality of death certification in Palestine.

\section{Methods}

\section{Study design and population}

A cross-sectional study was conducted to assess the physicians' knowledge and practice on completing the DNF. The study was conducted during the period Nov to Dec 2013 and targeted all physicians working at the governmental and nongovernmental hospitals in the North West Bank. Physicians not involved in care of in-patients and those working in the departments of radiology, pathology and dermatology, were excluded from the study.

Among the eligible physicians (600)working in 50 governmental and non-governmental hospitals, a sample size of 150 physicians was computed using a confidence level of $95 \%$, a precision of $5 \%$, and a $15 \%$ estimated proportion of optimal performance, through simple random sampling. To compensate for the nonresponse, we added an extra 50 physicians ( $25 \%$ of estimated sample) to the calculated sample size to include a total of 200 physicians.

\section{Data collection}

A self-administered questionnaire, to be completed in the English language, was used to collect data. It was adopted from previous studies $[11,12]$ and was pre-tested with a convenience sample of 20 physicians from the study population to ensure clarity, time and ease of administration. It included questions related to physicians' demographic characteristics and qualifications (the physicians' experience, training and practice in completing death certificates) and physicians' knowledge of death certificate completion, including the completion of a death certificate case scenario. A case scenario (Additional file 1) was included in the questionnaire and the physicians were asked to complete the cause of death section and then their answers were evaluated in terms of errors in completing the DNF.

Incorrect answers were classified as major and minor errors as described above in the introduction. The data abstraction sheet was constructed by the researchers based on national standards and international guidelines [4] to collect information regarding the errors in completing the COD section in the DNF. Researchers reviewed the DNF independently and any disagreements were resolved by consensus based on discussion.

Statistical Package for the Social Sciences (SPSS) version 20.0 was used for data entry and analysis. Proportions of completeness of COD and errors in reporting the COD section were calculated. A chi square test was used to assess the association between participants' characteristics and their responses. The level of significance was set at 0.05 .

Approval from the An-Najah National University institutional review board and the Palestinian Ministry of Health was obtained and consent forms were signed by physicians before completing the questionnaire. Participants' privacy and confidentiality of collected data were assured.

\section{Results}

A total of 150 physicians completed and returned the questionnaire giving an overall response rate of $75 \%$. The median age of the participants was 29 years, with ages ranging from 25 to 65 years. Male gender constituted $79.3 \%$ of the participants, and a majority of them (63.3\%) were working in governmental hospitals. Resident physicians constituted the majority of the sample (63.3\%).

The majority of participants $(82.7 \%)$ reported they had experience in completing the DNF, and only $21.3 \%$ of all participants reported that they received previous training for completing the DNF. Regarding their specialty, the sample was distributed almost equally, and about one fourth (26.7\%) were graduated from universities in Palestine (Table 1).

The majority of physicians who had experience in completing the DNF (62\%) reported facing difficulties in 
Table 1 Characteristics of study participants $(N=150)$

\begin{tabular}{|c|c|c|}
\hline Characteristic & $\begin{array}{l}\text { Frequency } \\
\text { Number }\end{array}$ & $\begin{array}{l}\text { Percentage } \\
(\%)\end{array}$ \\
\hline Age & Median 29 & $\begin{array}{l}\text { Range } \\
25-65\end{array}$ \\
\hline \multicolumn{3}{|l|}{ Gender } \\
\hline Male & 119 & 79.3 \\
\hline Female & 31 & 20.7 \\
\hline \multicolumn{3}{|l|}{ Current possession } \\
\hline Resident & 95 & 63.3 \\
\hline Specialist & 55 & 36.7 \\
\hline \multicolumn{3}{|l|}{ Work place } \\
\hline Governmental & 95 & 63.3 \\
\hline Non-governmental & 55 & 36.7 \\
\hline \multicolumn{3}{|l|}{ Graduation country } \\
\hline Palestine & 40 & 26.7 \\
\hline Other countries & 110 & 73.3 \\
\hline \multicolumn{3}{|l|}{ Years since Graduation } \\
\hline 1 year & 27 & 18.0 \\
\hline $2-5$ years & 58 & 38.9 \\
\hline $6-10$ & 30 & 20.1 \\
\hline 11 and more & 35 & 23.0 \\
\hline \multicolumn{3}{|l|}{ Specialty } \\
\hline Medicine & 28 & 18.6 \\
\hline Surgery & 54 & 36.0 \\
\hline Pediatrics & 22 & 14.7 \\
\hline Others & 46 & 30.7 \\
\hline \multicolumn{3}{|l|}{ Completed DNF Before } \\
\hline Yes & 124 & 82.7 \\
\hline No & 26 & 17.3 \\
\hline \multicolumn{3}{|c|}{ Trained to complete DNF } \\
\hline Yes & 32 & 21.3 \\
\hline No & 118 & 78.7 \\
\hline
\end{tabular}

completing it (Fig. 1). Dealing with complicated cases and the design of the DNF were the most common difficulties reported by physicians (Table 2).

Evaluating the results on the case scenario indicated that only $40.6 \%$ of the participants filled the COD section completely correctly. At least one major error was made by $44.3 \%$ of the physicians. The most common major error was "No underlying cause of death after mechanism of death" (17.3\%), followed by "Incorrect sequence" error (14.7\%) (Fig. 1).

For minor errors, only $15(10 \%)$ of DNF were free of any minor error. The most frequently occurring minor error by physicians was "Using abbreviations and symbols" error (84.7\%), followed by "Irrelevant information" error (45.3\%) (Fig. 2).

The frequency of major errors in the case scenario part was assessed in relation to physician characteristics. It was evident that female physicians made less major errors than male physicians. Major errors were less often made by specialists compared to resident physicians. Physicians who worked in governmental hospitals made more errors than those who worked in non- governmental hospitals; a "No acceptable cause of death" error was made by $11.6 \%$ of governmental hospital physicians compared with $3.6 \%$ in non- governmental $(P=0.020)$.

Physicians graduated from countries other than Palestine made more major errors than those graduated from local medical schools. Physicians with experience in completing the DNF made fewer errors than those who never filled a DNF before. (Table 3).

\section{Discussion}

Mortality statistics are one of the vital sources of information about health status and many research projects in many countries consider it as one of the most reliable source of health data. The errors in DNF have many significant effects on long term planning of the health systems in the national and international levels $[3,4]$.

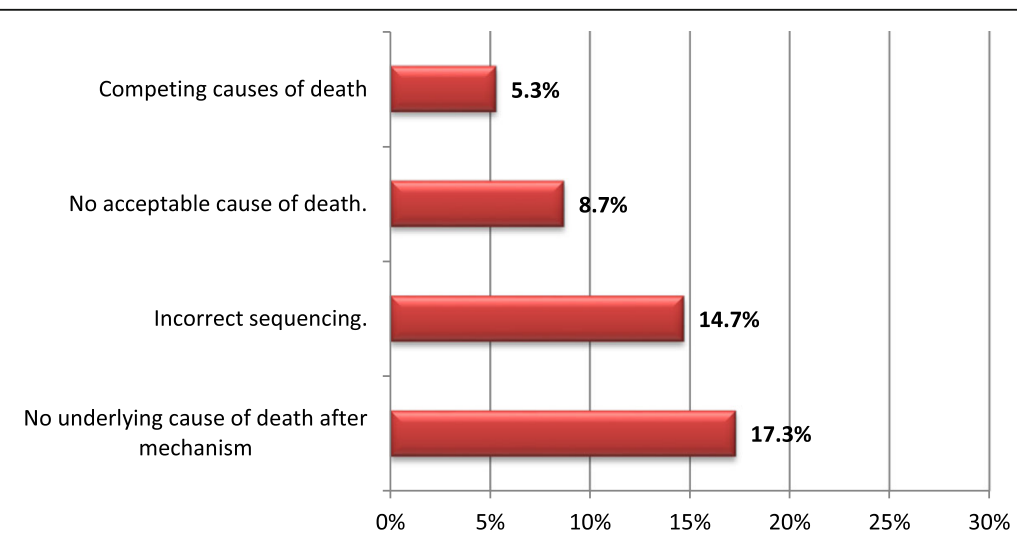

Fig. 1 Distribution of Major Errors in the Case Scenario $(n=150)$ 
Table 2 Distribution of difficulties when completing previous DNF $(N=77)$

\begin{tabular}{lll}
\hline Difficulty type & $\begin{array}{l}\text { Frequency } \\
\text { Number }\end{array}$ & $\begin{array}{l}\text { Percentage } \\
(\%)\end{array}$ \\
\hline Dealing with complicated cases & 50 & 64.9 \\
Problem in design of DNF & 37 & 48.1 \\
Lack of training & 30 & 39.0 \\
Did not understand terms & 22 & 28.6 \\
Lack of time & 16 & 20.8 \\
\hline
\end{tabular}

The majority of the present study participants were males $(79.3 \%)$, which is consistent with the distribution of the physician work force in Palestinian hospitals. More than half of the participants $(56.9 \%)$ were graduated 5 years ago or less, and this is in agreement with the results that showed that $63.3 \%$ of the participants were residents. This may be attributed to the new residency programs being applied in Palestinian hospitals.

Regarding the formal training on completing the DNF, only $21.3 \%$ of study participants reported that they had received training; this is consistent with other studies in the region like Qatar, Bahrain and Nigeria where the proportion of trained physicians were $22.7 \%, 19 \%$ and $29 \%$ respectively [11-13]. This low percentage of training could show the decreased importance of this subject perceived by Ministry of Health and other related organizations.

Surprisingly, only $40.7 \%$ of participants reported that they need to be trained on how to complete the DNF. The physician need for training in completing the DNF was addressed by many studies where variable results were obtained; 27.4\% of physicians in Qatar reported a need for further training compared to $77.6 \%$ physicians in Bahrain [11, 12]. Explanations could be that the participants didn't receive regular feedback on their DNF performance, so they might have believed that they already had the enough experience and practice on completing the DNF, and they might not be sufficiently aware of their errors and/or the importance of completing the DNF accurately.

Among the participants who had past experience on completing the DNF, about $62 \%$ of them reported previous difficulties during completing it. The "complicated cases" were the most common difficulty that the participants faced when completing a DNF (64.9\%); this is similar to what has been reported in a study conducted in Qatar [12]. This could be attributed to the poor documentation system in most of the hospitals where electronic filing is not being introduced yet; this makes physicians unable to extract complete medical information about the case. This can also explain why governmental hospital physicians did more errors in completion the DNF as they faced more complicated cases and have workloads with shortages of staff. "Problem in design of DNF" was the second most common difficulty reported by the participants. It is noticed that the clinical section of the national DNF deviates substantially from the WHO recommendations. It is not clearly distinguished from the whole document, especially the poor distinction between Part 1 and Part 2, which is a major problem for both certifiers and those producing statistics.

For individual errors observed in the case scenario, this study found that immediate cause of death was identified incorrectly by $51.3 \%$ of participants, which is lower than reported by other similar studies $[12,14]$. Terms that describe the mechanism of death (mostly cardio-respiratory arrest) were filled incorrectly instead of the "Immediate cause of death" in almost half of the case scenarios (49.3\%). Underlying cause of death was identified correctly by $71.3 \%$ of the participants compared to $58 \%$ of Qatari physicians [12].

We expect the results obtained in this study to have underestimated the errors committed by physician in their

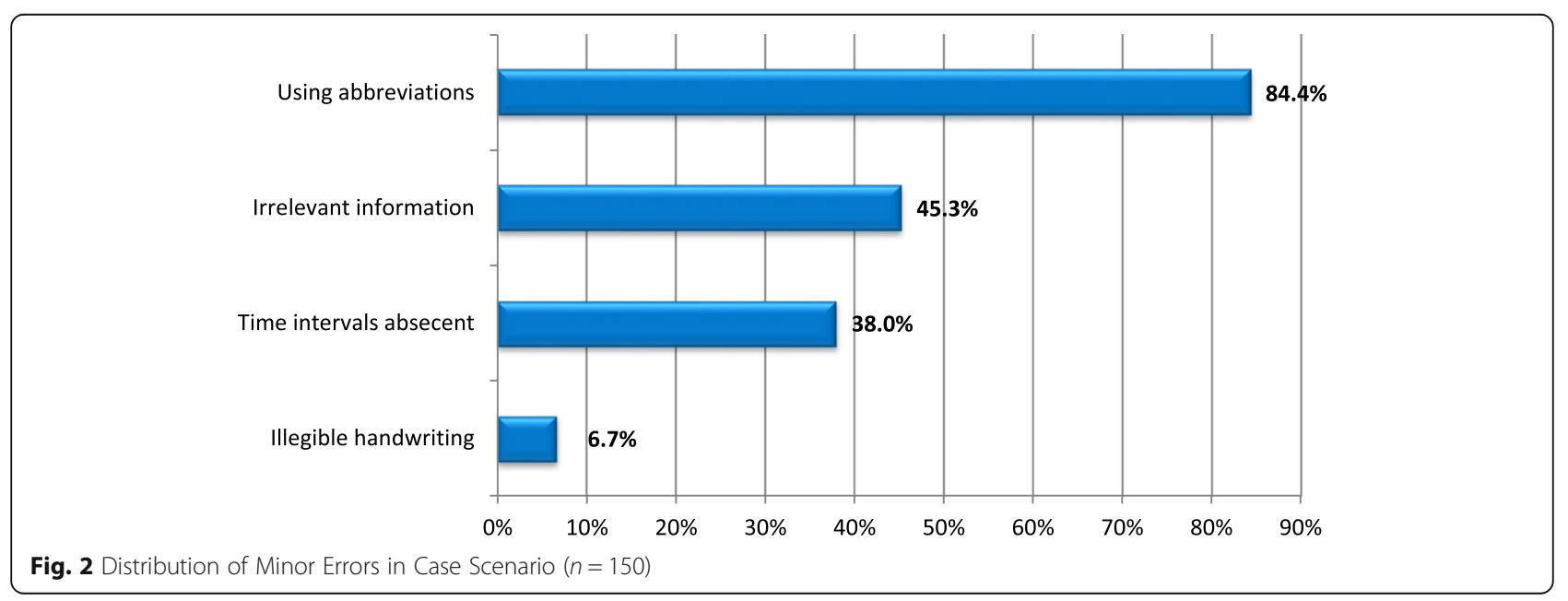


Table 3 Association between major errors in case scenario related to Physicians' characteristics

\begin{tabular}{|c|c|c|c|c|c|c|}
\hline \multirow[b]{3}{*}{ Characteristic } & \multicolumn{6}{|c|}{ Type of error } \\
\hline & \multicolumn{2}{|c|}{ Mechanism of Death } & \multicolumn{2}{|c|}{ Incorrect sequencing } & \multicolumn{2}{|c|}{ No acceptable cause of death } \\
\hline & $n(\%)$ & $P$-Value* & $n(\%)$ & $P$-Value & $n(\%)$ & $P$-Value* \\
\hline \multicolumn{7}{|l|}{ Gender of physician } \\
\hline Male & $22(18.4)$ & 0.464 & 20(16.8) & 0.147 & $11(9.2)$ & 0.623 \\
\hline Female & $4(13.0)$ & & $2(6.5)$ & & $2(6.5)$ & \\
\hline \multicolumn{7}{|l|}{ Current possession } \\
\hline Resident & $20(21.0)$ & 0.114 & 15(17.8) & 0.609 & $9(9.5)$ & 0.644 \\
\hline Specialist & $6(11.0)$ & & $7(12.7)$ & & $4(7.2)$ & \\
\hline \multicolumn{7}{|l|}{ Work place } \\
\hline Governmental & $17(18.5)$ & 0.727 & 15(15.8) & 0.523 & 11(11.6) & 0.020 \\
\hline Non-governmental & $9(16.4)$ & & $7(12.7)$ & & 2(3.6) & \\
\hline \multicolumn{7}{|l|}{ Graduation Country } \\
\hline Palestine & $4(10.0)$ & 0.306 & $1(2.5)$ & 0.011 & $0(0.0)$ & 0.023 \\
\hline Other country & $22(20.0)$ & & $21(19.2)$ & & $13(11.8)$ & \\
\hline \multicolumn{7}{|l|}{ Graduation year } \\
\hline$\leq 5$ years & $18(45.0)$ & 0.306 & $12(32.5)$ & 0.405 & $7(14.0)$ & 0.775 \\
\hline$>5$ years & $7(22.1)$ & & $7(27.6)$ & & 6(18.8) & \\
\hline \multicolumn{7}{|l|}{ Specialty } \\
\hline Medicine & $5(18.0)$ & 0.872 & $3(10.7)$ & 0.296 & $1(3.6)$ & 0.101 \\
\hline Surgery & $11(20.4)$ & & $6(11.1)$ & & $2(3.7)$ & \\
\hline Pediatric & $3(13.6)$ & & $6(27.3)$ & & $4(18.2)$ & \\
\hline Others & $7(15.2)$ & & $7(20.0)$ & & $6(13.0)$ & \\
\hline \multicolumn{7}{|l|}{ Completed DNF Before } \\
\hline Yes & $17(13.7)$ & 0.035 & 15(12.0) & 0.143 & $11(8.8)$ & 0.933 \\
\hline No & $9(34.6)$ & & $7(7.0)$ & & $2(7.6)$ & \\
\hline \multicolumn{7}{|l|}{ Trained to Fill DNF } \\
\hline Yes & $7(22.6)$ & 0.386 & $3(9.7)$ & 0.378 & $4(12.9)$ & 0.347 \\
\hline No & 19(16.0) & & 19(16.0) & & $9(7.6)$ & \\
\hline
\end{tabular}

${ }^{*}$ Chi-square test

real practice. In another study [15] conducted by the same authors, 547 real DNF were randomly selected from the primary health care directorates in the North West Bank to assess their quality and evaluate the most common type of error. In general, the errors observed in the case scenario in this study are much less than those observed in the real DNFs. This divergence may have different explanations: first, the physicians may have given more attention to answering the questionnaire (approaching it as an exam) than they do when completing an actual DNF. Second, being a self administrative questionnaire may have allowed physicians a chance to review the topic to provide "ideal" answers, or ask help from expert physicians in answering the questions. Finally, the case scenario that was included in the questionnaire could not have resembled the complexity of real life situations where different factors play a role in the physicians' ability to accurately identify different causes, including the patient's medical history, the quality of the medical records, and the length of time that the physician has been following the patients' condition prior to death. In addition to that, the circumstances in which the case scenario was filled give more time for the physician to think about the case compared with circumstances when he filled the actual DNF.

\section{Conclusion}

The study findings imply the need to increase physicians' awareness about the importance of DNF and their implications on improving their practice. This could be through offering training workshops on DNF completion and developing a manual on completing the DNF with clear instructions and guidelines. Medical schools should emphasize this issue and highlight its important in their 
curriculum. Improve the process of documentation in the health care institutes to increase the amount of available information about the patient in the hands of physicians. Finally, revision of the national DNF is needed to simplify it and make it consistent with the WHO recommendation. Thus, completing the DNF properly will improve accuracy of the national mortality report and, consequently, the evidence-based decision making.

\section{Additional files}

Additional file 1: Case scenario and its model answer. (DOCX 196 kb)

\section{Abbreviations}

COD: Cause of death; DNF: Death notification form; IRB: Institutional review board; $\mathrm{MOH}$ : Ministry Of Health; N(n): Number; SPSS: Statistical package for the social sciences; WHO: World Health Organization

\section{Acknowledgements}

We would like to acknowledge An-Najah National University (ANNU), the participants, and the hospital directors for their cooperation.

\section{Funding}

This work has entirely been made by the efforts and the financial support of the authors. No fund or financial assistance has been provided from other resources.

\section{Availability of data and materials}

The datasets supporting the conclusions of this article are presented and included in the results section of the main manuscript.

\section{Authors' contributions}

JQ has made substantial contributions to the conception and design of the study, the acquisition of data, the analysis and interpretation of the data, and the drafting of the manuscript. ZN also has made substantial contributions to the conception and design of the study, the acquisition of data, the analysis and interpretation of the data, and the drafting of the manuscript. AY has made substantial contributions to data collection and interpretation and to drafting the manuscript. MM has also made substantial contributions to data collection and interpretation, and to drafting the manuscript. All authors have given final approval of the version to be published.

\section{Ethics approval and consent to participate}

IRB at An-Najah National University. Approval from the An-Najah National University institutional review board and the Palestinian Ministry of Health was obtained and consent forms were signed by physicians before completing the questionnaire.

\section{Consent for publication}

The manuscript doesn't contain any individual person's data in any form.

\section{Competing interests}

The authors declare that they have no competing interests.

\section{Publisher's Note}

Springer Nature remains neutral with regard to jurisdictional claims in published maps and institutional affiliations.

\section{Author details}

${ }^{1}$ Faculty of Medicine and Health Sciences, An-Najah National University, PO box 7, Nablus, Palestine. ${ }^{2}$ Department of anesthesia, An-Najah National University Hospital, Nablus, Palestine. ${ }^{3}$ Department of general surgery, Palestine medical complex, Ramallah, Palestine.
Received: 15 April 2016 Accepted: 19 December 2017

Published online: 08 January 2018

\section{References}

1. Statistics South Africa. Cause of death certification: a guide for completing the notice of death / stillbirth - DHA-1663. Pretoria: Statistics South Africa; 2012.

2. Mathers CD, Ma Fat D, Inoue M, Rao C, Lopez AD. Counting the dead and what they died from: an assessment of the global status of cause of death data; 83:171-177C. Bull World Health Organ. 2005;83(3):171-c.

3. Centers for Disease Control and Prevention. Medical Examiners' and Coroners' handbook on death registration and Fetal death reporting. Hyattsville, Maryland: DHHS Publication; 2003. PHS2003-1110

4. U.S. Department of Health and Human Services, Centers for Disease Control and Prevention, National Center for Health Statistics. Physicians' handbook on medical certification of death. Hyattsville, Md: Government Printing Office; 2003. DHHS publication no. (PHS)2003-1108

5. Smith A, Hutchins GM. Problems with proper completion and accuracy of the cause-of-death statement. Arch Intern Med. 2001;161:277-84.

6. Maudsley G, Williams EM. Death certification by house officers and general practitioners-practice and performance. J Public Health. 1993;15(2):192-201.

7. Joubert J, Rao C, Bradshow D, Vos T, Lopez AD. Evaluating the quality of National Mortality Statistics from civil registration in South Africa, 19972007. PLoS One. 2013;8(5):e64592.

8. Wexelman B, Eden E, Rose K. Survey of new York City resident physicians on cause-of-death reporting, 2010. Prev Chronic Dis. 2013;10:120288.

9. Pritt BS, Hardin NJ, Richmond JA, Shapiro SL. Death certification errors at an academic institution. Arch Pathol Lab Med. 2005;129(11):1476-9.

10. Burger EH, Van der Merwe L, Volmink J. Errors in the completion of the death notification form. S Afr Med J. 2007;97(11):1077-81.

11. Ali A, Hamadeh R. Physicians' knowledge and practices in death certificate completion in the Kingdom of Bahrain. J Bahrain Med Soc. 2013;24(1):17-23.

12. Al-Kubaisi NJ, Said H, Horeesh N. Death certification practice in Qatar 2013. Public Health. 2013;127(9):854-9.

13. Izegbu M, gboola A, hittu L, Akiode O. Medical certification of death and indications for medico-legal autopsies: the need for inclusion in continue medical education in Nigeria. Sci Res Essay. 2006;1(3):61-4.

14. Venu RS, Bala DV. Evaluation of medical certification of cause of death in one of the teaching hospitals of Ahmadabad. Innovative J Med Health Sci. 2012;2(5):118-21.

15. Qaddumi J, Nazzal Z, Yacoup A, Mansour M. Quality of death notification forms in North West Bank/Palestine: a descriptive study. BMC Res Notes. 2017;10(1):154.

Submit your next manuscript to BioMed Central and we will help you at every step:

- We accept pre-submission inquiries

- Our selector tool helps you to find the most relevant journal

- We provide round the clock customer support

- Convenient online submission

- Thorough peer review

- Inclusion in PubMed and all major indexing services

- Maximum visibility for your research

Submit your manuscript at www.biomedcentral.com/submit
Ciomed Central 